\title{
Experience Design for Kids: Phygital Product for Augmented Pedagogy
}

\author{
Benedetta Terenzi ${ }^{1 *}$ and Francesca Pucciarini ${ }^{2}$ \\ ${ }^{1}$ Department of Civil and Environmental Engineering, University of Perugia, Italy \\ ${ }^{2}$ Department of Design, Polytechnic University of Milan, Italy
}

*Corresponding author: Benedetta Terenzi, Department of Civil and Environmental Engineering, University of Perugia, Italy.

To Cite This Article: Benedetta Terenzi, Experience Design for Kids: Phygital Product for Augmented Pedagogy. 2020 - 8(2). AJBSR. MS.ID.001249. DOI: 10.34297/AJBSR.2020.08.001249.

Received: 眥 March 02, 2020; Published: 些 March 16, 2020

\begin{abstract}
The paper aims to highlight the active role that some tools have assumed within the playful activity of today's children. It is intended to underline, how the connection of the digital world with the world of toys allows to expand the games from traditional ways to create new possibilities of play and active learning for an augmented pedagogy.
\end{abstract}

Keywords: Augmented Pedagogy, Playful Experience, Phygital Product, Kid-Centered Design, Digital Education, Edutainment, STEM, Smart Toys, Design for Kids

\section{Introduction}

One of the major differences between today's children's play and that of the past is the strong presence of tools to facilitate or influence the action of the game. Obviously, children have always played as far as they could, yet the ways, the gestures, the objects of their games have always been related to their culture and social conditions. But nowadays the awareness of the status of the game as a dynamic process, as a key facilitator for learning, and the fact that it reflects the social and cultural contexts in which children live, is more alive and shared in adults [1-3]. The game has been investigated for centuries focusing on its interesting reflections, sometimes even ambivalent concerns and feelings, coming from the religious and secular-bourgeois world [4]. The different theories in psychology and sociology agree in affirming that playful activity is fundamental for children: it is in fact necessary to learn to live daily experiences, for cognitive growth, to build skills, to socialize, for emotional development and physical and also to master emotional trauma [5].

Looking at Social Learning Theory, which has its main thinker in Jean Piaget [6,7], identity would be modeled based on social stimulus. Huizinga [8] states that it is culture itself that arises in a playful form "[...] every human action appears as a game. (...) I am more and more firmly convinced that human civilization arises and develops in the game ", that is, it is represented in playful forms and moods. The renewal carried out in the twentieth century, defined as the "century of children" [9] begins with the theories of the Swedish writer for a new idea of "motherhood" and "fatherhood" which focuses on infantile needs. It then continues with the educational transformations from school and activist pedagogy that gives voice and space to educational models based on the primacy of 'doing'. These positions leave significant traces in the current pedagogical reflection as a peculiar activity of the child, functional to the construction of the personality, which as such must be guaranteed in order to learn "playing the profession of man" [4].

It is significant now to highlight the increasingly active role that some shared knowledge has assumed within the playful activity of today's children, after the educational transformations coming to the fore in the eyes of pedagogists and parents in the last century from school and activist pedagogy. This awareness shared today is reflected in the design of the game tools, in which the real end user, the child, finally becomes an active part, even in the design and development phases of the tool itself. Alongside this, it is necessary to consider the way in which the vast sector of products for chil- 
dren has opened to the new potential offered by technology and digital innovation to respond to increasingly specific and constantly evolving needs. Today the design activity is oriented towards the Product Service System (PSS), that is, with an integrated mixture of products, communication strategies, services and spaces to offer innovative solutions

\section{Product Service System Design (PSSD) for Kids}

Let's see how the 'design for kids' sector is moving towards the User Centered Design logic [10]. The connection between the digital world and the world of toys allows you to expand games from traditional ways and thus create new possibilities for play and learning. Access to children's devices and electronic tools occurs at an ever-lower age. Digitization is a very important goal for many toy companies. Online games and apps are constantly increasing, which bridge the gap between the virtual and real world, in a very special way [11]. The most spoken language in the world is not English, but the 'code': Microsoft's Satya Nadella, defines it as 'poetry'. To teach it to children, the growing market trend is that of developing STEM toys (an acronym for Science, Technology, Engineering and Mathematics) in those forms in which the active role of the child is fundamental.

The development of technology, of new devices with which to communicate and interact, has given birth to a new era for "digital natives" [12]. They are the first generation that grew up with new technologies: they are those who prefer to process images or videos, rather than written texts. Faced with this evidence, the ways of learning must and are evolving. In this sense, the PSS Design approach incorporates innovative strategies that shift businesses away from simply designing and selling physical products to developing integrated systems of products and services that satisfy human needs.

\section{Digital in Support of a New Type of Learning}

Focusing on this point, it is appropriate to analyze what is the relationship between learning, new generations and technology. Although in fact the younger ones are comfortable with the use of new technologies, it should be emphasized that ability to use does not automatically mean understanding of the operating logic. According to Fomichov VA \& Fomiciova OS [13] the main social function of education is reproduction of culture. Their approach to solving educational problems is in line with the constructivist theory which states that knowledge is not only transmitted by a teacher to a student, but it is built into the mind of students during the process of active learning. That is why the educational process should be based, among other things, on the principles of Cognitonics. The goals of cultural enrichment, the development of cognitive mechanisms and intellectual and spiritual development of child must be jointly incorporated into contemporary educational processes in order to enhance the child's ability to properly process all information.
In the 1990s, Olga Fomichova created the Emotional-Imaginative Teaching System (EIT - system), which became part of the principal preconditions of developing in the 2000s (together with Vladimir Fomichov) the foundations of Cognitonics. According to Fomichov VA \& Fomichova OS [14] the aforementioned system aims at developing in individual: ability to process symbolic information; ability to observe and appreciate beauty in all its appearances, particularly in human activity; ability to understand others; understanding of so-called social agreement and social relationships; ability to have one's own point of view; sense of belonging to the generation as well as the understanding of those generations that were before and those that will develop later; and awareness of belonging to a particular national culture. In other words, this system aims to introduce a social, human component into education and can be perfectly integrated into goals of Cognitonics for the use of ICT.

It has also been observed that time spent with the technological tool is rarely productive or educational. Children should know the mechanisms and logic behind evolving technologies, as well as the basic functioning of the most common devices; they need to understand and exploit the potential of digital in the field of communication and innovation, but also in terms of collaboration and social inclusion. Children should learn how to develop a critical approach towards the reliability of media, information and available data and be aware of the ethical and legal principles that derive from the use of these tools. It is essential to promote an active approach to technology by the implementation of creative processes and design paths, overcoming the simple instrumental use. It is here that gaming can become a fundamental opportunity through which transmit some of these skills using an active approach.

About this John Dewey [15] underlines the difference between play as an activity and playfulness as an attitude; playfulness can also be present in situations that are not perceived as a game. Psychologist Mihaly Csikszentmihalyi defines this mental state of complete absorption as flow [16]. Csikszentmihalyi also argues that in the ideational process a fundamental role can be played by the surrounding environment. The creative surroundings [16] are those places whose conditions can facilitate the creative act, conditions that can also be determined by the grouping of people who share the same interests and passions, and which generate a stimulating atmosphere useful for the circulation of ideas.

The importance of the environment in the ideational and learning process has been repeated many times also by great personalities of the educational field, starting from Maria Montessori's [17] definition of a 'ambiente maestro' a space in which the child can find his independence through freedom of movement and exploration and in which order and simplicity, beauty of the artifacts and of the environment itself, contact with the surrounding nature, and the relationship with others are fundamental. On the same lines, the 
recent Scintillae space, result of the collaboration between Reggio Children Foundation-Center Loris Malaguzzi and Lego Foundation. Scintillae is a research project that studies the relationship between play and learning in the digital age based on the Loris Malaguzzi's atelier concept.

"The atelier is an environment that promotes knowledge and creativity, suggests questions and gives rise to suggestions. It is beauty that produces knowledge and vice versa" (Reggio Children Website) [18]. Montessori environment and Malaguzzi's atelier are perfectly in line with the principles of User Centered Design because they are conceived around the needs and specificities of the child. In the same way, therefore, the designer, who deals with education, game or product design, can build an all-round educational experience in which tools, spaces, educators and children themselves form a single creative moment expressed through the game and which, at the same time, can be part of the aforementioned product-service system logic.

The designer must also work on overlapping of various languages (coding, manual writing, musical language, drawing, etc.) as well as different thematic areas (humanistic and scientific) and mixing analogical and digital spheres. By synthesizing multiple elements from different dimensions, the child is offered the opportunity to create new connections, to approach art and recognize beauty, while learning to move in open systems where there is not just a single correct answer. The future-claims [19] will belong to those who manage to redefine and rethink the complex relationship between natural and artificial; who will be able to combine knowledge and skills; who will merge the two cultures (humanistic and scientific) both in terms of education and training, but also the definition of professional profiles and skills [19].

It is generally possible to classify the use of technology applied to toys as follows: AI (Artificial Intelligence), that is, toys with special features such as visual perception, voice recognition, translation, etc.; Machine Learning, that is, toys that can learn, behave according to patterns, change their actions according to stimuli and adapt to the player's ability; Internet of Toys (IoToys), that is, toys connected wirelessly to the Internet, to other toys and/or to database data; Virtual Reality, that is, toys with computer-generated simulation of a three-dimensional image or of an environment with which one can interact in real-time or physically by using special electronic equipment (helmet, glasses, gloves, etc.); Augmented Reality through the use of a smartphone or tablet's camera which provides a level of information, including text and/or images, that goes beyond the real world's vision [20].

The ability to design and develop 'spaces for learning and play' that are careful to balance and make dialogue between the dimensions of analogue and digital, natural and artificial, humanistic and scientific culture, with innovative content it has become a neces- sary skill to be solicited in all those realities that deal with education and development of gaming products for children.

\section{Methods}

\section{Development of New Phygital Products for an Augment- ed Pedagogy}

\section{Literature review}

In order to map the state of the art of the knowledge in this field, a literature review was carried out to identify the main needs of both children and adults in the digital learning sector. 10 articles were studied internationally from 2015 to 2019, in addition to the EU Kids Online and UNICEF sites. Thanks to the collaboration with the Kids \& Toys Osservatory of Polytechnic University of Milan was possible to identify the challenges and opportunities for the project of Phygital products to support learning.

From the analysis of the documents, a series of cross-cutting themes emerged:

I. Health concerns and issues regarding the limit on children's media consumption

II. Fears related to the digital socialization of children and their use of social media

III. The shortcomings of adults in terms of ability

IV. The mutual expectations of parents and teachers who have not been met

V. The gap between technical equipment and skills

VI. Attention to uses by children

VII. Communication between school and family.

\section{Ethnography research}

Subsequently, 2 focus groups were carried out which involved parents and teachers (20 people in total) to investigate and limit the problems encountered, and 2 workshops with children aged 4-10 years (total 30 children) to whom digital devices were provided with which to carry out pre-established assigned tasks. From these activities emerged the interesting opportunity to use the theme of environmental sustainability as a driver for the development of new Phygital products to support a new type of interactive and augmented learning.

\section{Case Studies}

\section{Innovative Solutions for Augmented Pedagogy}

Presented below the case studies by DENSA (Developing Edutainment for New Skills and Attitudes) designed based on the results obtained in the research phase. DENSA is a social enterprise whose mission is to build learning spaces through game in which children, teens and adults are encouraged to develop their attitudes 
to transform them into skills useful to design their professional and personal future, in order to-recovering one of the first concepts exposed in this article-learn "by play the profession of man". "Alberi Bambini" (Young Trees) is one of the environments designed and created by a team of technicians, trainers, architects and craftsmen with the aim of developing a sensory experience that recalls the theories of neurobiologist Stefano Mancuso, according to which trees communicate with each other and with the surrounding world.

The activity is designed for children from 2 to 12 years old and composed by two wooden tables that house 16 plants connected via circuits to a board (Figure 1) (Makey-Makey kit, produced by Joy Labz) able to transform the energy of contact between the hand and the plant in 16 different sounds amplified by an audio system. The same typology and heterogeneity of professionals involved in "Alberi Bambini" has contributed to design and develop "Il trasporto del futuro" (Transport of the future), a game and learning platform for 6-12 years old made of wood and inspired by the old games. Inside this wooden city, of which we can decide the density and the relationship between trees and buildings, the goal is to introduce the basics of coding through the programming of a robot with wheels (mBot Robot connected with mBlock Blockly App for iPad, both developed by Makeblock). In this case the learning experience focuses on the disclosure of one of the latest researches of Mit Senseable City Laboratory, founded by Carlo Ratti in collaboration with Mit Media Lab, which highlights how private cars are parked for 95 $\%$ of the time.

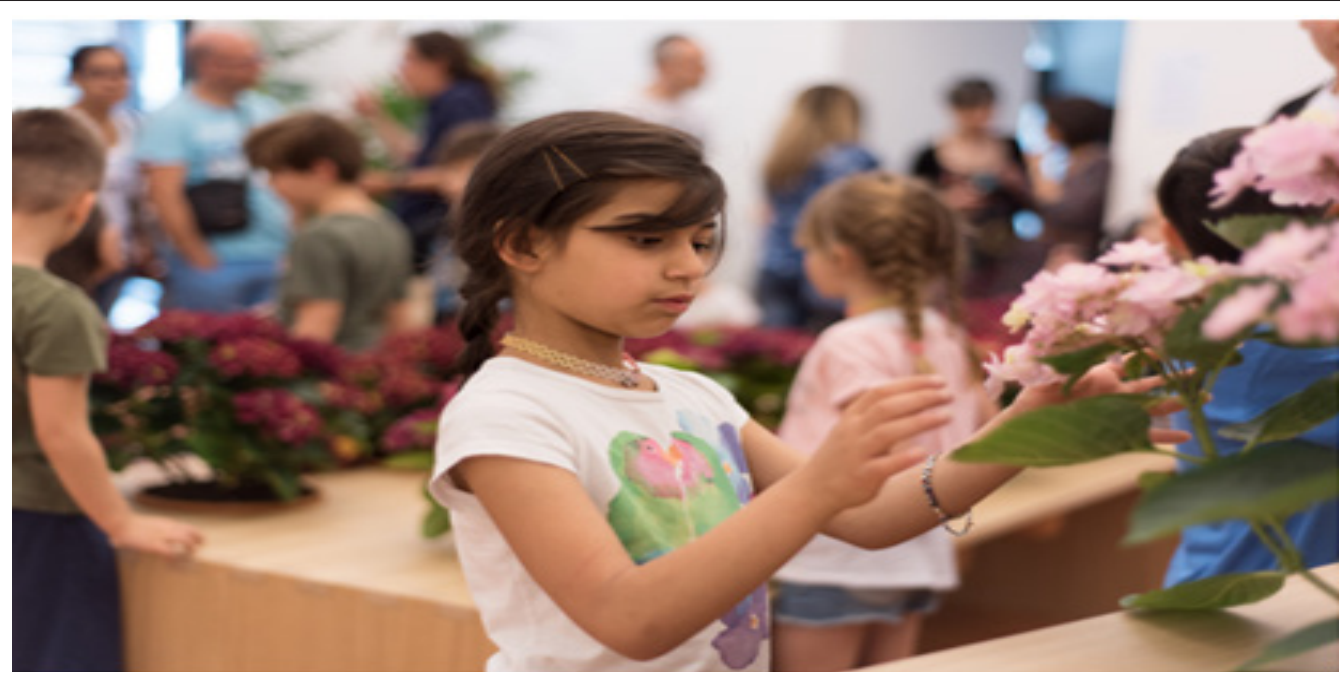

Figure 1: Alberi Bambini at Kids bit Festival, 2019.

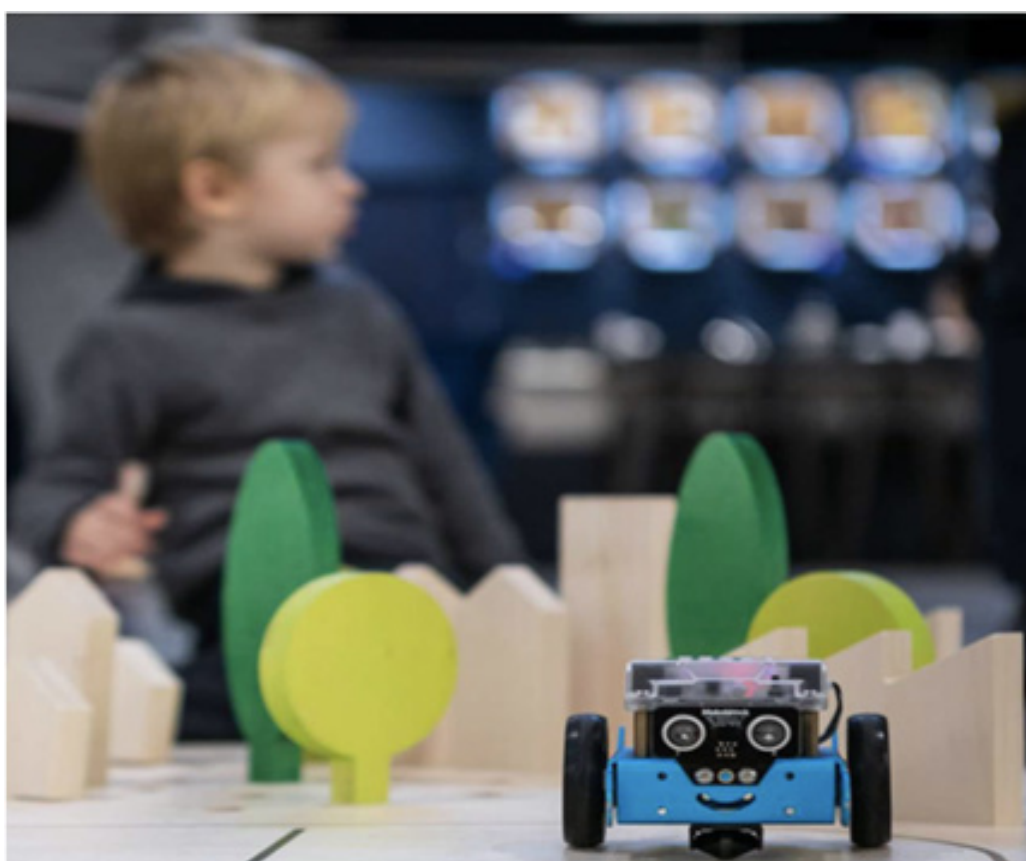

Figure 2: The Transportation of the Future, River Industries, 2019. 


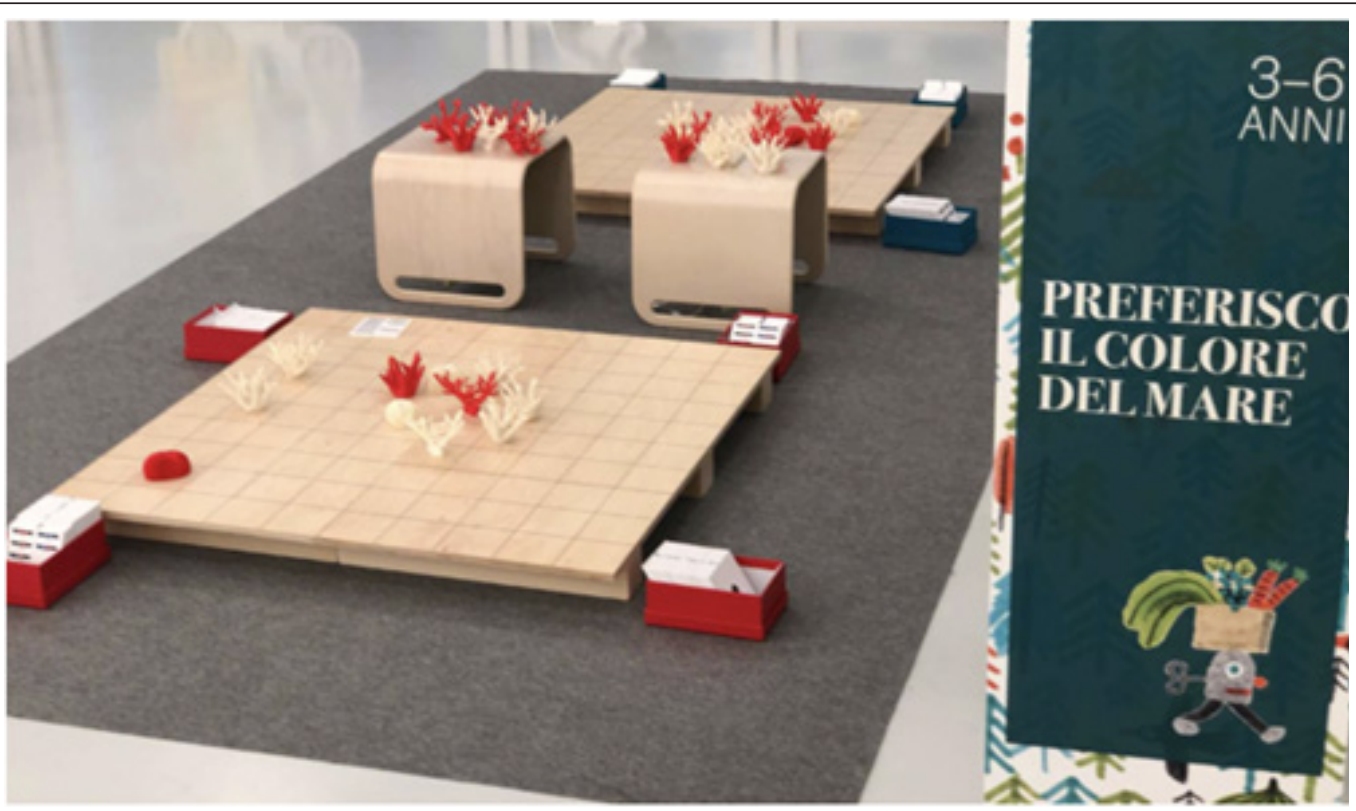

Figure 3: I prefer the color of the sea.

The transportation of the future leads children to design ways of moving in ecological cities capable of responding to the environmental needs (Figure 2). A mix of materials makes up the environment of "Preferisco il colore del mare" (I prefer the color of the sea) (Figure 3): wood, forex and PLA (the 3D printing compostable filament). Focused on the fragility of the sea and its inhabitants, the experience is designed to take place on wooden platform engraved with a grid and involves the participants (children from 6 to 9 years old) in imagining some paths that the robot Ozobot Bit (produced by Ozobot \& Evollve) will have to take to move from a point A to a point B. The points are reproductions of sick and healthy coral reef made with 3D printing process. The goal is to replicate the repopulating action of the habitats destroyed by climate change as researchers from Queensland University of Technology, supported by the Great Barrier Reef Foundation, are doing through a small robot.

\section{Conclusions}

Technology offers interesting opportunities but is often not considered as a medium or intermediary of qualified and targeted content, capable of creating new opportunities for play, learning and socialization. A self-referencing mode is almost always used as bait and is not projected towards the user. At the same time, today if we think about design for kids it is easy to understand the number and type of skills required to design a quality product, whatever it is [20]. The fundamental approach that qualifies designers in the development of new Phygital products in the service of an augmented pedagogy must therefore start from these considerations:

I. ICT has great potential for enhancing teaching and learning outcomes, but the realization of this potential depends much on how the teacher uses the technology.
II. A design process with an approach to 'learning and doing': in this way designers can direct the learning of behaviors and relationships between children, toys and all the elements involved in the user experience.

III. Observation of users and direct involvement of the community (parents, teachers, associations, schools, etc.): designers can use different tools to generate value, in particular observation of users (ethnographic approach and reading of the experience of the user in specific context and places). The input in the new design management process of the product service system is therefore moved with a continuous contact with the community of practice that acts in the learning process and in the correct psycho-physical and cognitive development of the children.

Possible barrier for the diffusion of this new Phygital products: accessibility. Constraints such as (a) lack of enough money, interests among educators, and administrators, lack of enough software, lack of political will all these factors will invariably affect the accessibility of ICT to the education sectors.

\section{References}

1. Christie J (2001) Play as a learning medium. Reifel S (Ed.). Theory in context and out, Westport, Ablex publishing, New York, USA 3: 358-365.

2. Fromberg DP (1998) Play issues in early childhood education. Seefeldt C (Ed.). The early childhood curriculum: A review of current research, $2^{\text {nd }}$ (Edn), Merrill, OH, Columbus, USA pp.190-212.

3. Fromberg DP (2002) Play and meaning in early childhood education. Allyn \& Bacon, Boston, USA p.14.

4. Staccioli G (2004) Cultures at stake, playful activities for learning. Carocci Faber, Roma, Italy. 
5. Isenberg J, Quisenberry N (1988) Play: A necessity for all children Journal Childhood Education. pp.138-145.

6. Piaget J (1962) Play, dreams, and imitation in childhood WW Norton, New York, USA.

7. Prensky M (2012) From digital natives to digital wisdom: hopeful essay for 21 century learning. Corwin Press, California, USA pp. 240 .

8. Huizinga J (2002) Homo Ludens, preface, Einaudi, Torino, Italy.

9. Key E (1906) The century of children, Bocca, Torino, Italy.

10. Terenzi B, Vignati A (2020) Digital Transformation in Product Service System for Kids. Design Tools for Emerging Needs. In: Ahram T, Karwowski W, Vergnano A, Leali F, Taiar R (Eds.). Intelligent Human Systems Integration 2020. IHSI 2020. Advances in Intelligent Systems and Computing, Springer Cham 1131: 228-234.

11. Cianfanelli E, Crescenzi P, Goretti G, Terenzi B (2019) Playful learning for kids with special educational needs. In: Bagnara S, Tartaglia R, Albolino S, Alexander T, Fujita Y (Eds.). IEA 2018 AISC 826 Springer Cham pp. 732-742.

12. Prensky M (2001) Digital Natives, Digital Immigrants. On the Orizon, MCB University Press, UK 9(5): 1-6.

13. Fomichov VA, Fomichova OS (2009) Cognitonics as an answer to the challenge of time, Proceedings of the $12^{\text {th }}$ nternational Multiconference Information society-IS 2009, Slovenia, Ljubljana. The Conference Kognitonika/Cognitonics, Ljubljana, Jožef Stefan Institute, Slovenia pp.431-434.
14. Fomichov VA, Fomichova OS (2011) A map of cognitive transformations realized for early socialization of children in the internet age. In Bohanec $\mathrm{M}$, et al (Eds.). Proceedings of the $14^{\text {th }}$ International Multiconference Information Society-IS 2011, The Conference Kognitonika/Cognitonics. Ljubljana, Jozef Stefan Institute pp.353-357.

15. Dewey J (1910) How We Think. DC Heath \& Co, Boston, MA, New York, USA pp.224.

16. Csikszentmihalyi M (1996) Creativy, Flow and the psychology of discovery and invention, Harper Perennial, New York, USA.

17. Montessori M (2000) The method of scientific pedagogy applied to children's education in children's homes, Critical Edition, Montessori National Opera Editions, Rome, Italy.

18. Reggio Children Foundation-Loris Malaguzzi Centre, Reggio Emilia, Italy.

19. Dominici P (1998) For a new media ethics. Elements for a critical discussion, Firenze Libri Ed, Florence, Italy.

20.Vignati A, Terenzi B (2019) Sustainable product-service for children's soft mobility. In: DeGiovanni G, Scalisi F (Eds.). Pro-innovation: Process, Production, Product 2: 253-266. 